terizada. Apesar de sua freqüência e abrangência etária, o primeiro consenso em língua portuguesa ou inglesa elaborado sobre 0 assunto só deve sair como suplemento no próximo número da Revista Brasileira de Otorrinolaringologia - RBORL 69(2).

Henrique Olival Costa Osmar Mesquita Neto

\section{Economia da Sacide}

Prevenção da transmissão MATERNO-INFANTIL DO HIV: É MAIS CARO IDENTIFICAR DO

\section{QUE TRATAR A GESTANTE SOROPOSITIVA}

A transmissão materno-infantil do HIV tornou-se passível de prevenção desde 1994 , quando foram publicados os resultados de um estudo multicêntrico, controlado, duplocego, com mulheres soropositivas (Connor 1994). Aquelas que receberam zidovudina (AZT) durante a gestação e o parto, e cujos recém-nascidos receberam zidovudina durante as seis primeiras semanas de vida, tiveram um risco de $8 \%$ de transmitir o HIV para seus filhos, enquanto que as que receberam placebo transmitiram o vírus em $25 \%$ dos casos. Medidas para prevenir a transmissão materno-infantil do HIV passaram a ser implementadas no Brasil desde 1996. Atualmente, as medidas recomendadas são: I) todas as gestantes devem receber o oferecimento do teste para o HIV, independente de qualquer avaliação de risco; 2) as gestantes soropositivas devem receber AZT via oral, em três doses diárias de $200 \mathrm{mg}$, a partir da $14^{\text {a }}$ semana até o final da gestação e, durante o trabalho de parto, AZT intra-venoso, na dose de $2 \mathrm{mg} / \mathrm{kg}$ de peso na primeira hora e $1 \mathrm{mg} / \mathrm{kg} /$ hora até 0 clampeamento do cordão umbelical - em caso de cesárea programada, a infusão intravenosa deve começar três horas antes do início da cirurgia; 3 ) todos os recém-nascidos expostos ao HIV devem receber AZT via oral, na dose de $2 \mathrm{mg} / \mathrm{kg}$, quatro vezes ao dia, durante seis semanas. $O$ aleitamento materno é contra-indicado. As gestantes que, pela evolução de sua condição clínica ou laboratorial, já estão em uso de terapia anti-retroviral devem avaliar os riscos e benefícios da manutenção desta terapia, principalmente no primeiro trimestre da gravidez. As gestantes que não estão em uso de anti-retrovirais, mas que se apresentam sintomáticas ou com parâmetros laboratoriais muito alterados, devem considerar o uso de terapia combinada. A cesariana é recomendada para as gestantes com carga viral desconhecida ou 1.000 cópias $/ \mathrm{ml}$ (Ministério da Saúde 200I).

\section{Comentário}

Embora a preocupação com os custos dos medicamentos venha permeando as principais discussões a respeito dos custos de tratamento dos pacientes soropositivos para o HIV, esta não deve ser a preocupação central no caso da prevenção da transmissão materno-infantil. Estudo em andamento, realizado pela autora, vem demonstrar que os custos dos medicamentos representam aproximadamente 5\% dos custos da prevenção, e que somente 0 rastreamento sorológico das gestantes representa cerca de $80 \%$ dos custos totais. Parte importante desses custos é devido as perdas e repetições desnecessárias dos testes. Com vistas ao uso eficiente dos recursos, é preciso estabelecer controles rígidos sobre os procedimentos laboratoriais que fazem parte da identificação da gestante soropositiva para o HIV.

Ana Maria Aratangy Pluciennik

\section{Referências}

I. Connor EM, Sperling RS, Gerber R, Kiselev $P$, Scott G, O'Sullivan MJ, et al. Reduction of maternal-infant transmission of human immunodeficiency virus type I with zidovudine treatment. NEngI J Med I 994; 33 I: I I73-80. 2. Ministério da Saúde. Recomendações para a profilaxia da transmissão materno-infantil do HIV e terapia anti-retroviral em gestantes. Brasília; 200I. (série manuais n.46).

\section{Emergência e Medicina Intensiva}

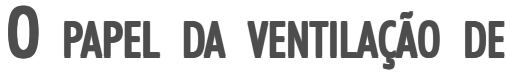
ALTA FREQÜÊNCIA OSCILATÓRIA (VAFO) NO PERíodo neONATAL

A ventilação mandatória intermitente (IMV) aliada às novas tecnologias de monitoração e ao uso de surfactante exógeno e óxido nítrico tem diminuído a mortalidade de recém-nascidos (RN) com insuficiência respiratória, aumentando a sobrevida de neonatos cada vez mais imaturos. Apesar de freqüentemente salvadora, a IMV está associada a diversas complicações decorrentes do baro/ volutrauma, como a síndrome de escape de ar ea displasia broncopulmonar (DBP). Tais fatos têm conduzido as pesquisas na busca de estratégias ventilatórias que provoquem menos lesões pulmonares, principalmente no pulmão imaturo. Dentro desse espírito, inserese a VAFO, que opera com freqüências respiratórias entre 600 a 800 ciclos por minuto e volumes correntes próximos ou abaixo do volume do espaço morto anatômico.

As vantagens da $\mathrm{VAFO}$ sobre a ventilação convencional foram comprovadas em pesquisas empregando modelos experimentais. 0 uso da VAFO resultou em insuflação pulmonar mais homogênea, melhor oxigenação e menor intensidade da lesão pulmonar. Tais fatos criaram a expectativa de que essa modalidade ventilatória, quando instituída precocemente no curso da insuficiência respiratória do RN, poderia prevenir ou reduzir a DBP, melhorando, assim, o prognóstico desses pacientes ${ }^{1,2}$. A revisão sistemática dos estudos clínicos controlados que avaliaram a eficácia do uso eletivo da VAFO em modificar a evolução clínica dos RN pré-termos portadores de síndrome do desconforto respiratório não comprovou claramente essa tese ${ }^{3}$. Observou-se uma pequena vantagem da VAFO sobre a IMV em reduzir a incidência de DBP. Entretanto, a VAFO não alterou a mortalidade e, além disso, observou-se uma tendência ao aumento de complicações neurológicas, como hemorragia intraventricular e leucomalácia periventricular, nos pacientes que receberam essa modalidade ventilatória.

Baseado na falta de evidências conclusivas de que a VAFO seja superior à convencional como modo primário de assistência respiratória e da possível associação dessa modalidade com complicações neurológicas, no momento, acreditamos que esta técnica deva ser reservada somente para os casos de falha da ventilação convencional como estratégia de resgate. Ou seja, recomenda-se a instituição da VAFO quando o índice de oxigenação [IO $=$ pressão média de vias aéreas $\left.x \mathrm{FiO}_{2} / \mathrm{PaO}_{2}\right]$ 
alcança a 20 durante a ventilação convencional. Na experiência de nosso serviço tal situação ocorre com maior freqüência nos $\mathrm{RN}$ que cursam com enfisema intersticial pulmonar grave, pneumotórax com fístula de alto débito, SDR grave, SAM acompanhada de hipertensão pulmonar, pneumonias congênitas e na hérnia diafragmática congênita.

\section{Comentário}

Como qualquer nova tecnologia introduzida na prática clínica, o uso da VAFO ainda segue a curva de aprendizado. Assim, o seu real papel e a melhor estratégia no manuseio de seus parâmetros no tratamento de neonatos com insuficiência respiratória ainda está por ser definida. Até o momento, as evidências indicam que a VAFO não deva ser considerada como uma alternativa e sim como uma terapia ventilatória complementar à ventilação convencional no manejo de $R N$ com insuficiência respiratória grave. Deve-se lembrar que as complicações observadas na ventilação convencional não ocorrem em menor freqüência durante a VAFO. Dessa forma, a introdução segura dessa modalidade ventilatória na prática médica exige um treinamento cuidadoso de toda equipe que lida direta ou indiretamente com o RN criticamente doente.

\section{Milton Harumi Miyoshi}

\section{Referências}

I. Johnson AH, Peacock JL, Greenough A, Marlow N, Limb ES, Marston L, et al. Highfrequency oscillatory ventilation for the prevention of chronic lung disease of prematurity. N Engl J Med 2002; 347:633-42.

2. CourtneySE, Durand DJ, AsselinJM, Hudak ML, Aschner JL, Shoemaker CT, et al. Highfrequency oscillatory ventilation versus conventional mechanical ventilation for very-lowbirth-weight infants. N Engl J Med 2002; 347:643-52.

3. Henderson-Smart DJ, Bhuta T, Cools F, Offringa $M$. Elective high frequency oscillatory ventilation versus conventional ventilation for acute pulmonary dysfunction in preterm infants. In: Sinclair J, Bracken M, Soll RF, Horbar JD, editors. Neonate Module of The Cochrane Database of Systematic Reviews [updated 28 Oct 2002]. Available from: URL: http:// www.nichd.nih.gov/cochraneneonatal.

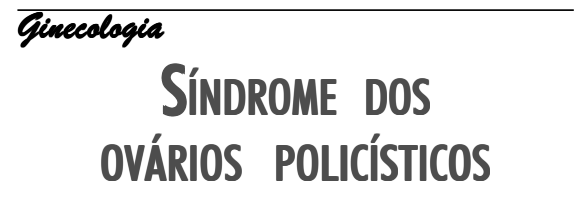

A Síndrome dos Ovários Policísticos (SOP)é doença endócrina complexa, que tem como elementos principais hiperandrogenismo e anovulação crônica. Caracteriza-se por irregularidade menstrual ou amenorréia e uma ampla gama de achados decorrentes do hiperandrogenismo: hirsutismo, acne, alopécia e seborréia. Representa uma das desordens endócrinas reprodutivas mais comuns em mulheres, acometendo em torno de $5 \%$ a $10 \%$ da população feminina em idade fértil.

\section{Diagnóstico}

O diagnóstico da SOP é de exclusão. A suspeita se fundamenta em irregularidade menstrual e sinais de hiperandrogenismo: hirsutismo, acne, aumento das concentrações séricas de testosterona total, livre ou de androstenediona. Nota: ovários policísticos ao ultra-som é dado inespecífico para o diagnóstico da síndrome, pois mais de $25 \%$ das pacientes com este achado são assintomáticas. Concentrações séricas de LH geralmente encontram-se elevados e de FSH normais ou baixos, embora $20 \%$ a $40 \%$ destas pacientes não apresentem estes achados, sendo as determinações de LH e FSH prescindíveis. O diagnóstico laboratorial da anovulação não está indicado, devendo ser clínico. A maioria das mulheres com SOP apresentam aumento da resistência à insulina $\mathrm{e}$ hiperinsulinemia compensatória, sendo que a determinação laboratorial da resistência à insulina não é essencial para o diagnóstico na prática clínica. Níveis séricos de prolactina e TSH são fundamentais para exclusão do diagnóstico de hiperprolactinemia ou hipotireoidismo. Níveis elevados de prolactina estão presentes em até $35 \%$ dos casos de SOP.É importante o diagnóstico da hiperplasia supra-renal congênita de instalação tardia, cujo quadro clínico pode ser indistingüivel ao da SOP. A exclusão de tumores produtores de androgênios do ovário ou da supra-renal é realizada através das concentrações séricas de testosterona e sulfato de dehidroepiandrosterona (DHEA-S).
Tratamento de sinais e sintomas do hiperandrogenismo

Hirsutismo e acne

- Anticoncepcional hormonal oral (ACHO): acetato de ciproterona, desogestrel, gestodeno;

- Espironolactona 50-200mg/dia;

- Acetato de ciproterona $50 \mathrm{mg} /$ dia com o esquema seqüencial reverso;

- Acne grave, encaminhar para tratamento especializado com o dermatologista;

- Flutamida 250mg/dia;

- Finasterida $5 \mathrm{mg} / \mathrm{dia}$;

- Cetoconazol e Glitazonas: efeitos colaterais limitam seu uso em larga escala;

\section{Tratamento Cirúrgico}

Atualmente sem maiores evidências de seus reais benefícios.

Irregularidade menstrual

- ACHO acima citados;

- Progestínicos na segunda fase do ciclo;

- B níveis de insulina. Metformina é a droga mais estudada, 1500 a $2000 \mathrm{mg} /$ dia.

\section{Controle do Peso}

A perda de peso é capaz de reverter os sinais e sintomas advindos do hiperandrogenismo.

Tratamento da infertilidade

Dieta e exercícios físicos representam o tratamento de primeira linha, melhorando a resistência à insulina e retorno dos ciclos ovulatórios, mesmo na ausência de perda de peso. A droga de escolha para indução da ovulação em pacientes com SOP é o citrato de clomifeno (CC), 50 a $200 \mathrm{mg} / \mathrm{dia}$ durante cinco dias, a partir do $3^{\circ}, 4^{\circ}$ ou $5^{\circ}$ dia do ciclo. Cerca de $50 \%$ a $80 \%$ das pacientes apresentam ovulação e $40 \%$ a $50 \%$ engravidam. Pacientes com SOP resistentes ao CC podem utilizar drogas que diminuem os níveis de insulina, isoladas ou em associação ao CC. A utilização isolada da metformina ( $1500 \mathrm{mg} /$ dia a $2000 \mathrm{mg} / \mathrm{dia}$ ) promove a ovulação em $78 \%$ a $96 \%$ das pacientes. Pacientes com níveis elevados de DHEAS são mais resistentes ao CC e podem beneficiar-se da administração de corticóide. A fertilização in vitro (FIV) pode 